\title{
Uniform Color of Placental Parenchyma
}

National Cancer Institute

\section{Source}

National Cancer Institute. Uniform Color of Placental Parenchyma. NCI Thesaurus. Code C117369.

The typical uniform coloring of the placental parenchyma irrespective of gestational age. 